\title{
Plasma oxalate concentration and secondary oxalosis in patients with chronic renal failure
}

\author{
C R V TOMSON, * S M CHANNON, $\dagger$ I S PARKINSON, $\dagger$ A R MORLEY $\ddagger$

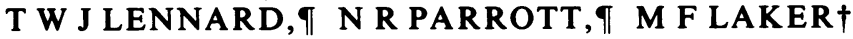

\begin{abstract}
From the Departments of ${ }^{*}$ Medicine, $\uparrow$ Clinical Biochemistry, $\ddagger$ Pathology, and $\uparrow$ Surgery, Medical School, University of Newcastle upon Tyne
\end{abstract}

SUMMARY To examine the association between hyperoxalaemia and secondary oxalosis, measurement of plasma oxalate concentration was combined with a search for tissue deposition of calcium oxalate crystals in patients with chronic renal disease. Two groups of patients were studied. In the first, samples of the inferior epigastric artery were taken from 35 patients at the time of renal transplantation. In the second, sections taken at necropsy from 23 patients with chronic renal failure in whom plasma oxalate had been measured before death were examined. Though plasma oxalate concentrations ranged between 6 and $116 \mu \mathrm{mol} / 1$ (four to 78 times greater than the upper limit of the reference range), no extrarenal deposits of oxalate were found in either study. Renal deposition of oxalate was associated with a plasma oxalate concentration of $>20 \mu \mathrm{mol} / \mathrm{l}$. This study gives no support to the suggestion that hyperoxalaemia of the degree seen in patients with the type of chronic renal failure that is not due to primary hyperoxaluria confers an appreciable risk of extrarenal oxalosis.

The accumulation of oxalate in patients with renal failure can cause serious damage to organs. This is most clearly seen in patients with primary hyperoxaluria in whom the development of renal failure is associated with rapid "accretion" of oxalate within the tunica media of muscular arteries, the cardiac conducting system, and the myocardium causing peripheral gangrene, conduction disturbances, and cardiomyopathy that progress and may be fatal despite dialysis. ${ }^{\prime 2}$ In patients who do not have primary hyperoxaluria the generation rate of oxalate is lower, but because no non-renal route of excretion exists for this metabolic end product, renal failure of any cause may result in similar, though less pronounced, accretion of oxalate within the tissues. This "secondary oxalosis" has been described, ${ }^{3-11}$ though in only a few of these cases could serious organ dysfunction be confidently attributed to the oxalate deposits. In addition, there is in vitro evidence that hyperoxalaemia may cause endothelial damage, raising the possibility that this is one factor that may lead to "accelerated atherosclerosis". 1213

These observations have led to interest in the determinants of hyperoxalaemia in renal failure on the assumption that tissue deposition is a function of local

Accepted for publication 5 May 1988 concentrations of calcium and oxalate. In the absence of plasma oxalate measurements in any of the reported cases of secondary oxalosis, however, the association between plasma oxalate concentration and tissue deposition remains unknown. We report studies in which, for the first time, measurements of plasma oxalate concentration by a reliable method have been combined with histological examination of tissue for the presence of oxalate deposits.

\section{Patients and methods}

HISTOPATHOLOGICAL EXAMINATION OF THE INFERIOR EPIGASTRIC ARTERY

A series of 35 patients undergoing cadaveric renal transplantation was studied. There were 20 men and 15 women, mean age 40 years (range 17-62). At the time of transplantation 20 patients were receiving haemodialysis, 13 continuous ambulatory peritoneal dialysis, and two intermittent peritoneal dialysis. Plasma samples for determination of oxalate concentrations were taken preoperatively and separated within 24 hours. At the time of operation the external iliac artery, and where possible the internal iliac artery, were assessed for palpable arterial disease on a three point scale (normal, mild atherosclerosis, and severe atherosclerosis) by the surgeon. In addition, $1-2 \mathrm{~cm}$ of 
the inferior epigastric artery (which is normally tied off during the operation) was taken for histological examination. Ten sections were stained using haematoxylin and eosin, and two each with van Gieson's, von Kossa's, Perls's, aluminon, and solochrome azurine stains. Each section was examined without knowledge of the clinical details or the plasma oxalate concentration under normal, partially polarised, and fully polarised light, conditions under which calcium oxalate deposits may be clearly recognised as positively birefringent crystals. For each subject the known duration of chronic renal failure, duration of renal replacement treatment, hypertension (blood pressure $>170 / 95$ on three occasions or the necessity for antihypertensive drugs) both before and since starting dialysis, smoking, primary renal disease, and history of nephrotic syndrome or diabetes mellitus were recorded.

\section{HISTOPATHOLOGICAL EXAMINATION AT} NECROPSY

In February 1986 we started a cross sectional study of plasma oxalate concentrations in all patients with chronic renal failure under the care of the Newcastle renal units. The preliminary results of this study have been reported. ${ }^{14}$ Twenty three patients from this study group died and underwent necropsies between
February 1986 and September 1987 (table 1). In these patients plasma oxalate had been measured a median of two months (range 1-11) before death. At the time of death eight patients were receiving haemodialysis, four continuous ambulatory peritoneal dialysis, and three intermittent peritoneal dialysis. Total time on dialysis ranged between 1 and 176 months. In addition, one patient had recovered function after four months on continuous ambulatory peritoneal dialysis, five had not yet started dialysis ("chronic renal failure"), and two patients had died with functioning renal transplants. There were nine women and 14 men aged between 27 and 75 . Sections of kidney were taken from 20 of 23 patients, of heart from 22 of 23 , of lungs from 21 of 23, and of liver from 19 of 23 . In addition, sections of thyroid, spleen, adrenal glands, pancreas, prostate, and brain were taken from some patients. All sections taken at necropsy were examined under polarised light for oxalate deposits without knowledge of the plasma oxalate concentrations.

For patients receiving haemodialysis, plasma urea concentration before dialysis (data not given), and creatinine, type of dialysis membrane, number of hours receiving dialysis, and body weight were recorded for each three month period since presentation. To give an index of the adequacy of dialysis, $\mathrm{Kt} / \mathrm{V}_{\text {urea }}$ was calculated, where $\mathbf{K}$ is in vivo dialyser urea clearance

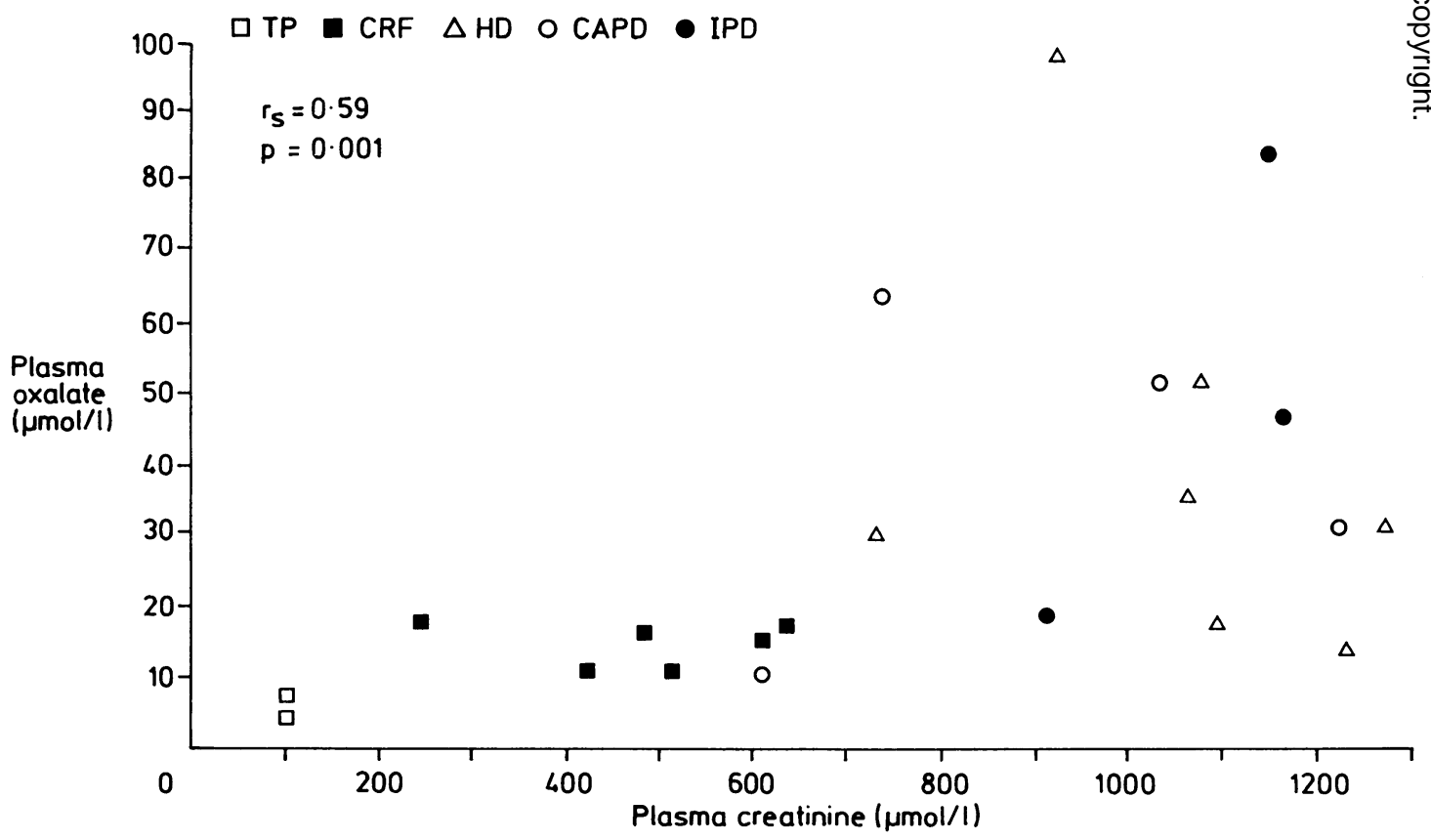

Fig 1 Plasma oxalate and plasma creatinine in patients at necropsy. TP = patients with functioning transplants, CRF $=$ patients with chronic renal failure not currently requiring dialysis (including the one patient with recovery of renal function), $H D=$ patients on haemodialysis, $C A P D=$ patients receiving continuous ambulatory peritoneal dialysis, IPD $=$ patients receiving intermittent peritoneal dialysis. 
Table 1 Causes of death in patients undergoing necropsy

\begin{tabular}{ll}
\hline Cause of death & $\begin{array}{l}\text { No of } \\
\text { patients }\end{array}$ \\
\hline Myocardial infarction & 4 \\
Heart failure & 7 \\
Hypertensive encephalopathy & 1 \\
Peripheral gangrene & 2 \\
Dissecting aneurysm & 1 \\
Pulmonary embolism & 1 \\
Peritonitis & 1 \\
Perforated duodenal ulcer & 1 \\
Septicaemia & 1 \\
Cessation of treatment & 1 \\
Uncertain & \\
\hline
\end{tabular}

( $\mathrm{ml} /$ minute) at $200 \mathrm{ml} /$ minute blood flow, $\mathrm{t}$ is dialysis time in minutes, and $\mathrm{V}$ is total body water in $\mathrm{ml}$, calculated as $60 \%$ of body weight. In patients receiving dialysis three times a week, a Kt/V of $>1$ is associated with enhanced survival, ${ }^{15}$ and is a commonly used "target" when assessing adequacy of dialysis, at least as regards clearance of small molecules. Because ascorbic acid has been reported to cause hyperoxalaemia in patients receiving dialysis, ${ }^{161718}$ dosage of ascorbic acid supplements was also recorded. For patients receiving peritoneal dialysis, urea, creatinine, ascorbate dosage, and weight were recorded for each three month period but no calculation of "adequacy of dialysis" was attempted.

\section{PLASMA OXALATE ASSAY}

Plasma oxalate was measured using an enzyme/ bioluminescent assay ${ }^{19}$ modified by immobilising the bioluminescent enzymes in a continuous flow cell. ${ }^{20}$ The reference range for this assay is $\langle 0.8-1.5 \mu \mathrm{mol} / 1$, $0.8 \mu \mathrm{mol} / 1$ being the detection limit. Unlike many other assays which overestimate plasma oxalate concentrations, this is in close agreement with the reference range derived from isotope dilution experiments. We have found that oxalogenesis (the spontaneous generation of oxalate in samples left unseparated) does not occur within 24 hours in samples from uraemic patients, probably because of inhibition by oxalate of the enzymes responsible.

\section{STATISTICAL METHODS}

Data were analysed with the Statistical Package for the Social Sciences. Descriptive statistics were not calculated for the necropsy study because of the heterogeneous nature of the study group.

\section{Results}

\section{HISTOPATHOLOGICAL EXAMINATION OF THE} INFERIOR EPIGASTRIC ARTERY

\section{Plasma oxalate concentrations}

Plasma oxalate concentrations ranged between 6 and $116 \mu \mathrm{mol} / \mathrm{l}$ (median $24 \mu \mathrm{mol} / \mathrm{l}$ ). Some patients were called up for transplantation having recently completed a dialysis session; plasma oxalate concentra-

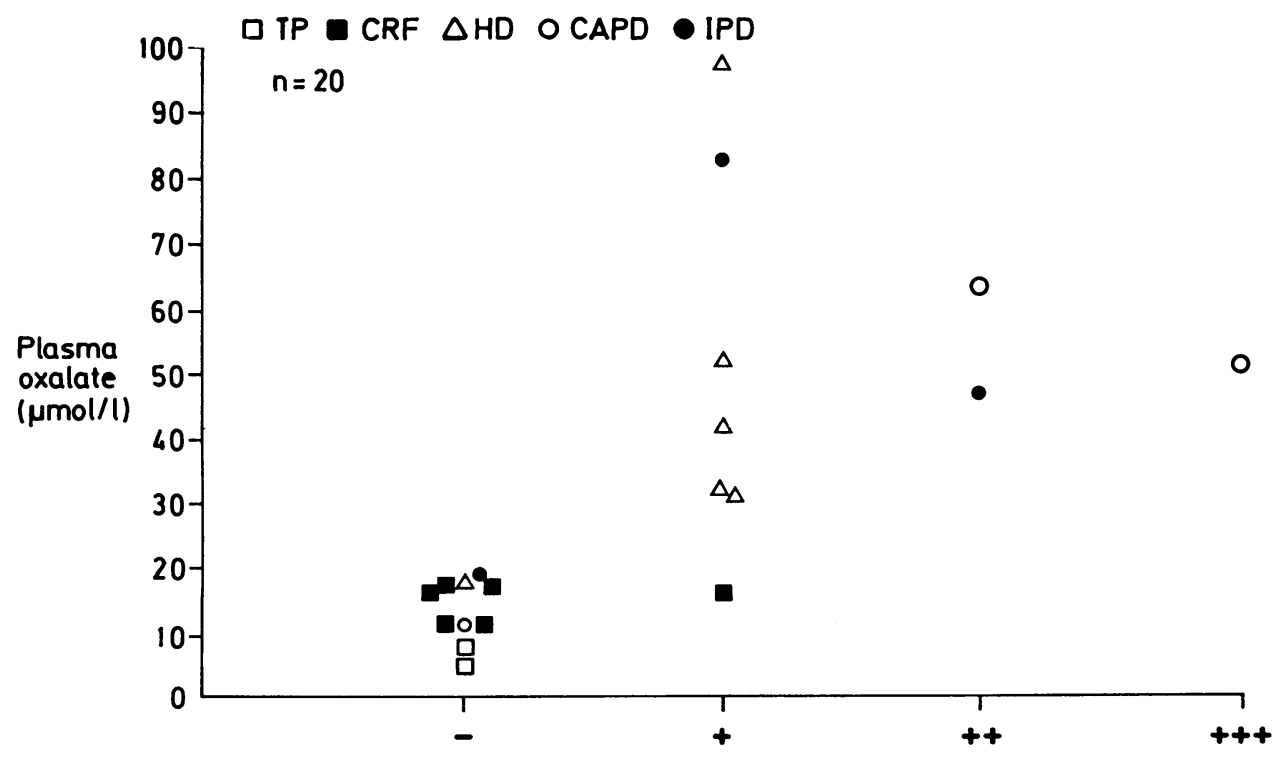

Fig 2 Plasma oxalate in patients with and without calcium oxalate deposits within the kidney detected by examination of histological sections taken at necropsy under polarised light. In three patients sections of kidney were not taken at necropsy. 
Table 2 Summary of clinical details and treatments

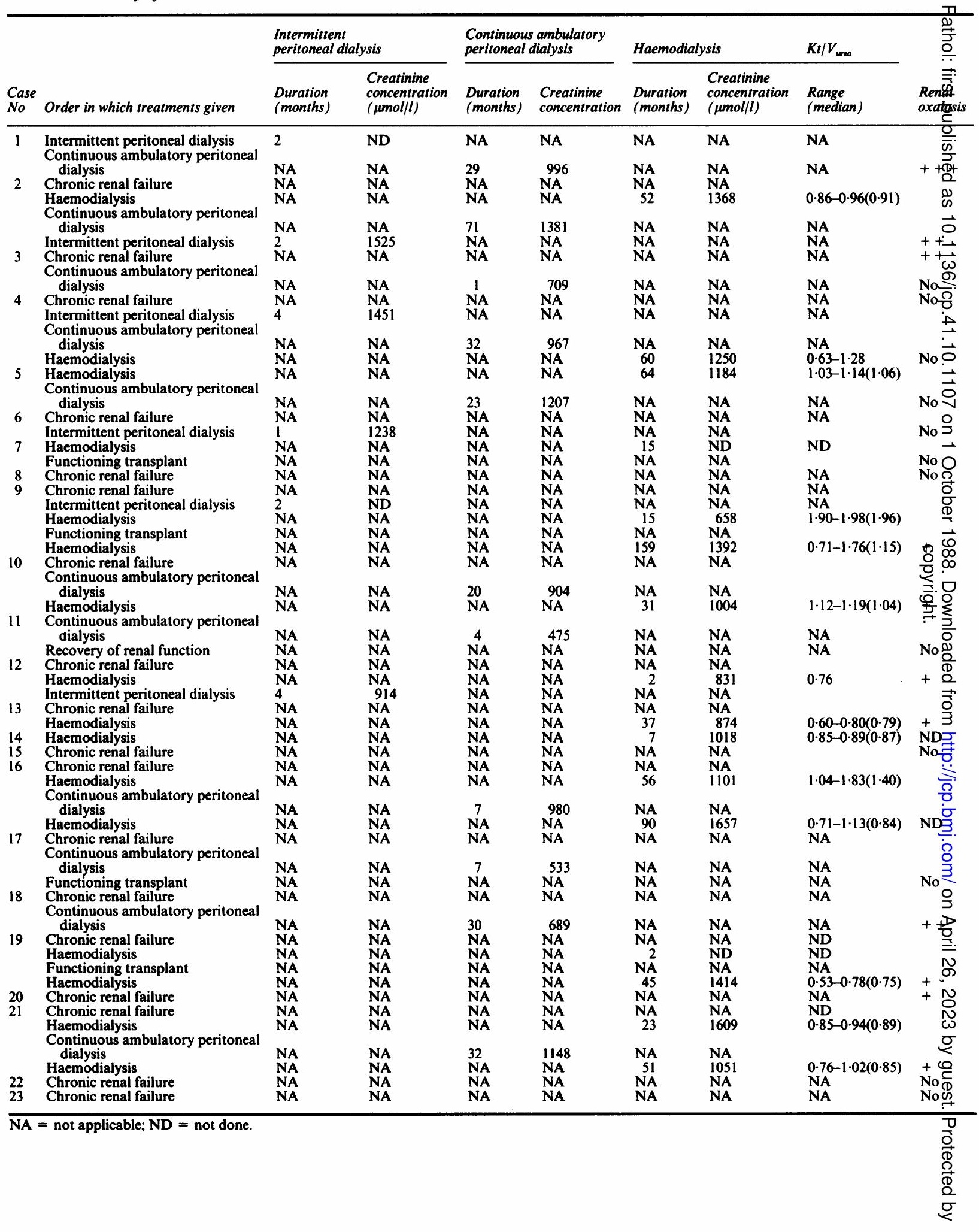


tions fall by about half during dialysis ${ }^{21}$ and ambient plasma oxalate concentration in these patients is therefore likely to have been higher than the measurement obtained before transplantation.

\section{Clinical appearances of iliac arteries}

The external iliac artery was clinically normal in 33 patients and mildly atheromatous in two. The internal iliac artery was clinically normal in 14 patients, mildly atheromatous in five, severely atheromatous in two, and not examined in 14 .

\section{Histopathology}

Fibrous intimal thickening was found in 20 of 35 arteries, and affected over half the circumference in 10 of 35. No lipid deposition was seen.

Diffuse, punctate staining for calcium was seen in sections stained with von Kossa's stain in the tunica media of seven of 35 arteries. Plaques of "solid" calcification disrupting the normal anatomy of the tunica media were seen in two arteries, one from a type 1 diabetic and one from a patient with severe hyperparathyroidism.

Diffuse, punctate staining within the tunica media was also seen with Perls's stain in two cases. The results of staining for aluminium were equivocal.

Examination of each section under partially and fully polarised light showed no birefringent crystals apart from the occasional easily recognisable talc crystals.

\section{Clinical correlations}

The length of time that patients had been receiving renal replacement treatment varied between one and 171 months (mean 51.8 months). Hypertension had preceded the onset of end stage renal failure in 19 of 26 patients; the remaining nine patients had presented in end stage renal failure. Hypertension had been present in 20 of 33 patients while on dialysis; adequate information was not available for two. Three patients had had the nephrotic syndrome in the past, and two were type 1 diabetics. Four patients were smokers, four had smoked in the past, and 22 gave no history of smoking: in five the smoking history was not known.

Analysis by the $\chi^{2}$ test showed no significant association between any of these potential risk factors and either intimal thickening or medial calcification. The mean age was significantly higher in the groups with medial calcification than in the group without $(48.6$ (SD 10.4), compared with 36.5 (SD 11.5) years, $t=$ $-2 \cdot 75, p=0.01)$. There was no significant association between duration of renal replacement treatment and any aspect of arterial histopathology. Comparison of plasma oxalate concentrations between groups with or without intimal thickening, and with or without medial calcification, showed no differences.
HISTOPATHOLOGICAL EXAMINATION AT NECROPSY

\section{Plasma oxalate concentrations}

Plasma oxalate measurements had been obtained between one and 11 months (median two months) before death during our cross sectional survey. Values ranged between 7 and $98 \mu \mathrm{mol} / \mathrm{l}$ and showed a positive rank correlation with concurrent plasma creatinine $\left(r_{s}=0.59, p=0.001\right)$ (fig 1). All samples were taken before dialysis. Ten of 18 patients receiving dialysis had been prescribed ascorbate supplements at some time, and three were taking them at the time of death. No association was found between current or cumulative dose of ascorbate and plasma oxalate.

\section{Histopathology}

Causes of death determined at necropsy are summarised in table 1. Oxalate deposits were found in 10 of 20 sections of kidney, and were graded subjectively as $+=$ mild,$+=$ moderate, and $+++=$ severe . The association between plasma oxalate concentrations and renal oxalosis is shown in fig 2 . No oxalate deposits were found in any other organ.

CLINICAL DATA

It is difficult to describe succinctly the "adequacy" of dialysis over prolonged time periods in patients who were frequently changed from one type of renal replacement treatment to another. Table 2 summarises the dialysis history of each patient.

\section{Discussion}

Although the numbers in this study are small, we found no evidence of extrarenal oxalosis despite severe hyperoxalaemia in some patients, and no evidence that hyperoxalaemia acts as a risk factor for vascular disease. This is in contrast to the published reports on secondary oxalosis, ${ }^{3-11}$ in which oxalate was readily detected by techniques similar to those that we usedexamination of paraffin wax embedded and stained sections under polarised light.

The reasons for this difference are not clear. Our patients were not particularly well dialysed as judged by mean plasma urea and creatinine concentrations and by the calculated $\mathrm{Kt} / \mathrm{V}_{\text {urea }}$ index, which if anything overestimates what actually happens in patients in whom adequate blood flow could not be achieved during haemodialysis. No comparable data are available for the previously described cases of secondary oxalosis, ${ }^{3-11}$ although many of them date from a time when dialysis was not as widely used nor as highly developed as it is now, and it is possible that small molecule clearances were worse than in many of our patients. Our patients received moderate doses of ascorbate, an oxalate precursor, even at a time when larger doses were fashionable; again, no comparable 
information is available apart from that in the reports of O'Callaghan et al and Ishida and Yamanaka, "and the contribution of ascorbate supplementation to secondary oxalosis (as opposed to hyperoxalaemia) remains uncertain.

No attempt was made in our study to undertake retrospective assessment of protein or oxalate intake, but severe protein restriction has never been used in Newcastle and no attempt has ever been made to prescribe a diet specifically low in oxalate. Recently it has been shown that extremely small aggregates of calcium oxalate formed after intravenous injection of sodium oxalate in rats are not readily detected by polarised light microscopy, ${ }^{22}$ and we may have failed to detect such small aggregates. This failure, however, would not help to explain the differences between our findings and those of previous investigators. The most likely explanation is that the dialysis regimens used in the patients described in these reports were inferior to those used in our patients, but high doses of ascorbate may have contributed.

Previous histopathological studies in arteries taken from uraemic patients $\mathrm{s}^{232425}$ have also shown a remarkable absence of lipid deposition, prominent intimal fibrosis, and medial calcification. Ibels $e t a l^{23}$ found correlations between the degree of intimal thickening and the duration of renal disease, and between the presence of arterial calcification and both duration of hypertension and duration of renal disease. Vincenti $e t$ $a l^{4}$ found a similar association between the presence of hypertension and arterial disease in a subgroup of patients aged between 25 and 40, and a significant correlation between age and degree of atherosclerosis in the group as a whole. In these studies the renal and iliac, ${ }^{23}$ iliac, $^{24}$ and radial ${ }^{25}$ arteries were studied; the inferior epigastric artery may be less prone to atherosclerosis and therefore less representative. Despite this the findings in our study are similar to those previously reported.

In conclusion, our study provides the first evidence of the association between the risk of tissue oxalate deposition and plasma oxalate concentrations in patients receiving dialysis. Plasma oxalate concentrations of $>20 \mu \mathrm{mol} / \mathrm{l}$ seem to confer a risk of renal oxalosis, but the importance of this in the management of dialysis patients is minimal. Plasma oxalate concentrations of up to $100 \mu \mathrm{mol} / 1$ have not been shown to be associated with histologically detectable extrarenal tissue deposition of calcium oxalate in the patients we studied, some of whom were receiving long term dialysis. It seems likely that plasma oxalate concentrations were higher than this in the patients previously reported. Until further evidence becomes available there is no justification for measures designed to reduce plasma oxalate concentrations below $100 \mu \mathrm{mol} / \mathrm{l}$.
We thank the Northern Counties Kidney Research Fund, the Wellcome Trust, and the Newcastle District Scientific and Research Committee for financial assistance; the staff of the dialysis units of the Royal Victoria Infirmary and Freeman Hospital for their cooperation; Dr M K Ward, Dr R Wilkinson, Dr R W Elliott, Professor J R Farndon, Mr G Proud, and $\mathrm{Mr}$ R M R Taylor for their permission to report their patients; and the staff of the histopathology laboratory at the Royal Victoria Infirmary for preparing the histological sections. Mr M Rose kindly translated reference 3 .

\section{References}

1 Jacobs C, Rottembourg J, Reach I, Legrain M. Terminal renal failure due to oxalosis in 14 patients. Proceedings of the European Dialysis and Transplant Association 1975;11:359-65.

2 Arbus GS, Sniderman S. Oxalosis with peripheral gangrene. Archives of Pathology 1974;97:107-10.

3 Bednar B, Jirasek A, Stejskal J, Chytil M. Die sekundare uramische oxalose. Zentralbl Allg Pathol 1961;201:289-97.

4 Bennett B, Rosenblum C. Identification of calcium oxalate crystals in the myocardium of patients with uremia. Lab Invest 1961;10:947-55.

5 Lewis RD. Lowenstam HA, Rossman GR.' Oxalate nephrosis and crystalline myocarditis. Archives of Pathology 1974;98:149-55.

6 Salyer WR, Keren D. Oxalosis as a complication of chronic renal failure. Kidney Int 1973;4:61-6.

7 Salyer WR, Hutchins GM. Cardiac lesions in secondary oxalosis Arch Intern Med 1974;134:250-2.

8 Fayemi AO, Ali M, Braun EV. Oxalosis in hemodialysis patients Arch Pathol Lab Med 1979;103:58-62.

9 O'Callaghan JW, Arbuckle SM, Craswell PW, Boyle PB, Searle JW, Smythe WR. Rapid progression of oxalosis-induced cardiomyopathy despite adequate haemodialysis. Miner Electrolyte Metab 1984;10:48-51.

10 op de Hoek CT, Diderich PPNM, Gratama S, Weijs-vHofwegen EJM. Oxalosis in chronic renal failure. Proceedings of the European Dialysis and Transplant Association 1980;17:730-5.

11 Ishida $\mathrm{K}$, Yamanaka N. Oxalosis in chronic renal failure or chronic dialysis or both. Nippon Hinyokika Gakkai Zasshi 1980;17:1423-31.

12 Boogaerts MA, Hammerschmidt DE, Roelant C, Verwilghen RL, Jacob HS. Mechanisms of vascular damage in gout and oxalosis: crystal induced, granulocyte mediated, endothelial injury. Thromb Haemost 1983;50:576-80.

13 Levin RI, Jaffe EA, Weksler BB, Kantoff PW, Minick CR. The effect of sodium oxalate on human endothelial cells. Circulation 1982;66(suppl II):11-39.

14 Tomson CRV, Channon SM, Parkinson IS, et al. Plasma oxalate in patients receiving continuous ambulatory peritoneal dialysis. Nephrol Dial Transplant 1988;3295-9.

15 Gotch FA, Sargent JA. A mechanistic analysis of the National Cooperative Dialysis Study. Kidney Int 1985;28:526-34.

16 Pru C, Eaton J, Kjellstrand C. Vitamin C intoxication and hyperoxalaemia in chronic hemodialysis patients. Nephron 1985;39:112-6.

17 Balcke P, Zazgornik J, Schmidt P, Kopsa H, Haubenstock A. High dose vitamin $\mathrm{C}$ administration is harmful in patients on regular dialysis therapy. Proceedings of the European Dialysis and Transplant Association 1985;22:147-51.

18 Ono K, Hisaue Y, Morimatsu M. Should vitamin C supplementation be restricted in regular hemodialysis patients? Trans Am Soc Artif Intern Organs 1986;32:111-3. 
19 Parkinson IS, Kealey T, Laker MF. The determination of plasma oxalate concentrations using an enzyme/bioluminescent assay. Clin Chim Acta 1985;152:335-45.

20 Parkinson IS, Adonai LR, Channon SM, Tomson CRV, Ward MK, Laker MF. The measurement of oxalate in biological fluids using an immobilised enzyme/bioluminescent assay. Ann Clin Biochem 1987;24(suppl 1):227-8.

21 Ramsay AG, Reed RG. Oxalate removal by hemodialysis in endstage renal disease. Am J Kidney Dis1984;4:123-7.

22 Blumenfrucht MJ, Cheeks C, Wedeen RP. Multiorgan crystal deposition following intravenous oxalate infusion in the rat. $J$ Urol 1986;135:1274-9.
23 Ibels LS, Alfrey AC, Huffer WE, Craswell PW, Anderson JT, Weil R. Arterial calcification and pathology in uremic patients undergoing hemodialysis. Am J Med 1979;66:790-6.

24 Vincenti F, Amend WJ, Abele J, Feduska NJ, Salvatierra O. The role of hypertension in hemodialysis-associated atherosclerosis. Am J Med 1980;68:363-9.

25 Ejerblad S, Ericsson JLE, Eriksson I. Arterial lesions of the radial artery in uraemic patients. Act Chir Scand 1979;145:415-8.

Requests for reprints to: Dr C R V Tomson, Department of Medicine, Clinical Sciences Building, Leicester Royal Infirmary, PO Box 65, Leicester LE2 7LX, England. 